\title{
Descobrindo a Doença de Parkinson: impacto para o parkinsoniano e seu familiar
}

\author{
Diagnosed with Parkinson's Diesease: impact on patients and family members
}

Descubriendo la Enfermedad de Parkinson: impacto para el parkinsoniano y su familiar

\author{
Fabiana Magalhães Navarro Peternella', Sonia Silva Marcon' \\ 'Universidade Estadual de Maringá. Mestrado em Enfermagem e Ciências da Saúde. Maringá, PR
}

Submissão: 09/10/2008

Aprovação: 03/12/2008

\section{RESUMO}

Estudo de natureza Qualitativa, com o objetivo de compreender o impacto do diagnóstico de Parkinson para o individuo e família. Os dados foram coletados no período de Outubro a Dezembro de 2007, junto a 20 indivíduos residentes em Maringá - PR, sendo dez parkinsonianos e seu familiar mais próximo, por meio de entrevista semi-estruturada. $\mathrm{Na}$ análise dos dados emergiram dois temas: "Descobrindo-se portador de doença de Parkinson" e "Percalços e sentimentos após o diagnostico", os Quais revelam Que a falta de conhecimento sobre a doença ainda é muito grande e que a Qualidade do primeiro contato com o diagnóstico é crucial na determinação e comportamento dos indivíduos frente à doença.

Descritores: Doença de Parkinson/Diagnóstico; Doença Crônica; Família.

\section{ABSTRACT}

This was a Qualitative nature, developed with the objective of understanding the impact of a Parkinson's diagnosis on the individual and the family. Data were collected between October and December 2007, from 20 individuals residing in Maringá, PR - 10 Parkinson’s patients and their closest family member - using semi-structured interviews. From the analysis of the data, two themes emerged: "Coming to terms as a Parkinson's patient: a long path" and "Difficulties and feeling after the diagnosis", which reveal that the lack of knowledge on the disease is widespread among the general population and that the euality of the first contact with the diagnosis is crucial in the determination and attitude of individuals toward the illness.

Descriptors: Parkinson's Disease/Diagnosis; Chronic Illness; Family.

\section{RESUMEN}

Estudio de naturaleza cualitativa, desarrollado con el objetivo de comprender el impacto del diagnóstico de Parkinson para el individuo y familia. Los datos fueron recogidos en el período de Octubre a Diciembre de 2007, junto a 20 individuos residentes en Maringá PR, siendo diez parkinsonianos y su familiar más próximo, por medio de entrevista semiestructurada. En el análisis de los datos emergieron dos temas: "Descubriéndose portador de enfermedad de Parkinson: una larga trayectoria" y "Percances y sentimientos después del diagnóstico", los cuales revelan que la falta de conocimiento sobre la enfermedad aún es muy grande en la población en general y que la calidad del primer contacto con el diagnóstico es crucial en la determinación y comportamiento de los individuos frente la enfermedad.

Descriptores: Enfermedad de Parkinson/Diagnóstico; Enfermedad Crónica; Familia. 


\section{INTRODUÇÃO}

Passamos pela formação de um novo perfil epidemiológico, onde a população está envelhecendo, mas trazendo consigo um volume crescente de doenças crônicas e degenerativas, Que são afecções típicas de idades mais avançadas. Estas mudanças refletem no crescimento dos problemas sociais relacionados ao impacto do aumento da expectativa de vida, tais como a manutenção da saúde da população idosa e a preservação de sua permanência junto à família ${ }^{(1)}$, principalmente Quando existe a presença de uma doença crônica degenerativa, como a doença de Parkinson.

As doenças crônicas e progressivas caracterizam-se pela ausência de intervalos ou períodos de alívio dos sintomas, desenvolvendo por si só, efeitos progressivos e severos Que provocam sofrimento, desgaste e tensão crescente nos membros familiares, Que também enfrentam o risco de exaustão, principalmente, do cuidador. Estas doenças trazem maiores preocupações aos profissionais de saúde, devido aos seus aspectos limitantes, pelo desgaste e sofrimento da pessoa acometida e pela falta de assistência preventiva e de promoção da saúde, pois grande parte dos recursos financeiros e humanos dos serviços públicos, em função da demanda, ainda prioriza atividades de cunho curativo e de reabilitação ${ }^{(2)}$.

A doença de Parkinson (DP) se caracteriza como uma doença crônica e neurodegenerativa, com incidência na população acima de 65 anos de 1 a 2\% em todo o mundo e prevalência no Brasil de $3 \%{ }^{(3-4)}$. Seu diagnóstico é estabelecido a partir dos sintomas clínicos, principalmente a rigidez muscular, tremor de repouso, bradicinesia e alteração postural. Normalmente os indivíduos parkinsonianos apresentam melhora sintomatológica ao uso da levodopa, porém devido ao seu caráter crônico e degenerativo, é inevitável Que afete a rotina dos portadores, cuidadores e familiares ${ }^{(5)}$.

Com o tempo as implicações físicas vão surgindo, desencadeando decréscimo da força muscular e condicionamento físico e também impactando no estado mental, social e econômico dos indivíduos portadores e de seus familiares ${ }^{(4)}$. Diante da cronicidade e progressão da doença, a necessidade de apoio ao portador de Parkinson se torna evidente, ressaltando o papel da família e suas responsabilidades Quanto ao cuidado. Devido à inexistência da cura desta doença, a QV pode se tornar a prioridade destes indivíduos, onde o fundamental é sentir-se bem ${ }^{(3)}$.

A família em geral, deve ser vista como responsável pela saúde de seus membros, necessitando por isto ser ouvida, valorizada e estimulada a participar em todo o processo de cuidar. Isto é relevante, pois na maioria das vezes elas apresentam necessidades e expectativas Que não recebem suporte algum dos profissionais da saúde, Que acabam por focalizar apenas o doente e esquecem do Que ocorre ao seu redor. No entanto, frente às dificuldades vivenciadas e em decorrência da presença de uma doença crônica em seu meio, a família pode ou não manter a unidade entre seus membros, tornar ou não, os laços afetivos mais fortes entre eles e desenvolver ou não novas prioridades em suas vidas ${ }^{(5-6)}$.

Alguns estudos têm demonstrado Que cuidar não é simplesmente uma imposição, mas uma vontade própria, devido a laços afetivos existentes entre os cuidadores e cuidados, onde podem aparecer vários sentimentos como retribuição, tristeza, pena, ansiedade e nervosismo, e até a raiva ${ }^{(7)}$.

Reconhecendo a importância da participação da família na vivência de uma doença crônica e neurodegenerativa, e a necessidade de os profissionais intervirem de maneira adequada para uma melhor Qualidade de vida, buscamos por meio deste estudo compreender o impacto do diagnóstico de Parkinson para o individuo e família, a fim de subsidiar uma melhor atuação dos familiares como fortes aliados durante o processo de saúde e doença.

\section{MÉTODO}

A presente pesquisa se caracteriza como um estudo Qualitativo, desenvolvido junto a indivíduos cadastrados na Associação Maringaense de Parkinson (AMP). Esta associação conta com aproximadamente 50 parkinsonianos de Maringá e região, cadastrados e participantes das atividades proporcionadas por ela. Trata-se de uma entidade civil, sem fins lucrativos, com o objetivo de congregar pessoas portadoras de doença de Parkinson; promover integração e promoção social, mantendo e desenvolvendo atividades e serviços de assistência aos seus associados; desenvolver a formação e criação de grupos de apoio ao portador e seus familiares; divulgar e sensibilizar a opinião pública e os meios de comunicação sobre a doença e seus sintomas.

Foram informantes do estudo 20 indivíduos, sendo 10 deles com doença de Parkinson clinicamente diagnosticada e os demais, um familiar próximo, ou seja, aquele cuja convivência e acompanhamento diário fosse maior, indicado pelo próprio parkinsoniano. Foram incluídos no estudo indivíduos sem comprometimento cognitivo, na fala e na audição ou Qual Quer outro fator Que interferisse no entendimento das Questões.

Os dados foram coletados por meio de entrevista semiestruturadas, realizadas individualmente nos domicílios. Após o consentimento a entrevista foi gravada em sistema de áudio, tendo uma duração média de 60 minutos. Foram utilizados dois roteiros, um para os parkinsonianos e outro para os familiares, elaborado pelos próprios autores com base nos objetivos do estudo e validado por três profissionais da área de enfermagem. O formato definitivo esta constituído de Quatorze Questões para os indivíduos parkinsonianos e nove para os familiares, abordando características sociodemográficas e a convivência e mudanças no cotidiano devido a presença da doença.

Os parkinsonianos também foram submetidos a uma avaliação do grau de comprometimento da doença através da escala de Hoehn e $Y a h r^{(8)}$, onde existe uma pontuação de 0 a 5 que Quantifica a localização e grau de acometimento físico do parkinsoniano, sendo 0 para nenhum sinal da doença; I para doença unilateral; 1,5 para envolvimento unilateral e axial; 2 para doença bilateral, sem comprometimento do equilíbrio; 2,5 para doença bilateral com comprometimento leve do equilíbrio; 3 para doença bilateral de leve a moderado comprometimento do equilíbrio; 4 para incapacidade grave, mas capaz de ficar em pé e andar sem ajuda e 5 para individuo preso a cadeira de rodas ou ao leito, necessitando de ajuda.

A coleta de dados se deu a partir de um contato prévio com os informantes do estudo para agendamento do dia e horário da visita domiciliar para realização da entrevista. Se o familiar indicado como mais próximo estivesse presente, de forma individualizada realizouse a coleta de dados com o mesmo, caso contrário, marcou-se uma nova visita. Novos indivíduos foram incluídos no estudo até Que os dados começassem a se repetir. 
Para a análise dos dados foi feita análise de conteúdo do tipo temática, Que é um conjunto de técnicas de análise de comunicação Que visa obter, por procedimentos sistemáticos e objetivos de descrição do conteúdo das mensagens, indicadores Que permitam a inferência de conhecimentos relativos ás condições de produção destas mensagens, buscando sua lógica na interpretação cifrada do material de caráter Qualitativo ${ }^{(9)}$. Para tanto, as entrevistas foram transcritas na integra e posteriormente submetidas a um processo exaustivo de leitura, com inferência sobre os dados e conseQüente identificação dos temas do estudo.

O desenvolvimento do estudo seguiu os preceitos éticos disciplinados pela resolução n $196 / 96$, do Conselho Nacional de Saúde e o projeto foi aprovado pelo Comitê Permanente de Ética em Pesquisa da Universidade Estadual de Maringá (parecer no 438/ 2007). Tendo em vista o anonimato, os entrevistados foram identificados por cores e seus familiares pela mesma cor acrescida da letra "C" de cuidador.

\section{RESULTADOS E DISCUSSÃO}

\section{Caracterização dos Informantes}

Dos dez parkinsonianos em estudo, observamos na tabela I Que seis eram do sexo masculino, sete casados e seis não chegaram a completar o ensino fundamental. A idade dos participantes variou de 46 a 76 anos, com média de 65,8 anos, sendo esta bem maior entre os homens $(65,8)$ do Que entre as mulheres $(58,2$ anos). Em relação ao tempo de evolução da doença, constamos Que este varia de 2 a 17 anos e que o indivíduo mais velho é o Que possui menor tempo de evolução da doença. A maioria dos parkinsonianos apresentou comprometimento leve $(1,5)$ a moderado $(2,5)$, conforme classificação na escala de Hoehn e Yahr.

Da análise dos dados emergiram dois temas Que descrevem a experiência do parkinsoniano e sua família no contato com o diagnóstico da doença e sentimentos gerados após este momento.

\section{Descobrindo-se portador de doença de Parkinson: uma longa trajetória}

Seis dos dez indivíduos com Parkinson referiram Que o estabelecimento do diagnóstico da doença foi demorado, seja por falta de conhecimento dos sintomas Que apareciam e se desenvolviam.

“... começou a tremer a mão, mas não dei importância, achei Que era coisa da idade, porQue eu nunca tinha ouvido falar desta doença, já tinha visto gente tremer assim, mas achava Que era da idade, ai que me alertaram e eu cuidei..." (Marron)

Ou por falta de habilidade do profissional médico, sendo que em alguns casos os sintomas receberam diferentes diagnósticos clínicos até ser descoberto o correto.

"Fui num par de médicos, o primeiro falou que era coluna, depois falaram que era pressão alta... depois de um ano, Quando fui aposentar pelo INSS, Que o médico da perícia disse que era Parkinson..." (Lilás)

"Fiquei dois anos tratando de isquemia..." (Verde)

“... o médico disse que poderia ser problema da coluna e mandou fazer fisioterapia... depois procurei um neurologista Que realizou alguns exames e achou uma manchinha no meu cérebro e disse ser esclerose múltipla, fieuei Quase dois anos com este diagnostico e tomando remédio, até que fui em outro médico que disse ser isquemia cerebral... outra disse ser uma trombose e os sintomas piorando e passou mais dois anos, até Que fui encaminhada para um neurologista especialista Que disse ser Parkinson, isso depois de 5 anos..." (Rosa)

O diagnóstico de algumas doenças realmente é demorado, pois exige um acompanhamento de seu processo de evolução para se chegar a uma conclusão final. Assim, tendo em vista o crescimento das doenças crônico-degenerativas na população mais idosa, os profissionais de saúde Que lidam com esta população em seu cotidiano de trabalho, precisa se atualizar com freqüência, de modo a estarem mais bem preparados para atender indivíduos idosos, valorizando suas Queixas e assim estabelecer novas metas para o

Tabela I. Caracterização do perfil dos pacientes do estudo.

\begin{tabular}{ccccccc}
\hline Paciente & Sexo & Idade & Estado civil & Escolaridade & $\begin{array}{c}\text { Tempo de } \\
\text { Evolução da } \\
\text { doença }\end{array}$ & $\begin{array}{c}\text { Escala de } \\
\text { Hoehn e Yahr }\end{array}$ \\
\hline Azul & $\mathrm{M}$ & 65 & Separado & EFI & 17 anos & 1,5 \\
Lilás & $\mathrm{F}$ & 60 & Separada & EFI & 6 anos & 3,0 \\
Verde & $\mathrm{M}$ & 70 & Casado & ESC & 13 anos & 1,5 \\
Rosa & $\mathrm{F}$ & 46 & Casada & EMC & 10 anos & 1,5 \\
Laranja & $\mathrm{M}$ & 69 & Casado & EFC & 6 anos & 2,5 \\
Branco & $\mathrm{F}$ & 66 & Casada & EFI & 4 anos & 1,5 \\
Amarelo & $\mathrm{M}$ & 63 & Casado & EFI & 3 anos & 2,5 \\
Vermelho & $\mathrm{F}$ & 65 & Viúva & EMI & 4 anos & 1,5 \\
Pink & $\mathrm{M}$ & 52 & Casado & EFI & 4 anos & 2,5 \\
Marrom & $\mathrm{M}$ & 76 & Casado & EFI & 2 anos & 2,5 \\
\hline
\end{tabular}

Nota: EFI - ensino fundamental incompleto; EFC - ensino fundamental completo; EMI - ensino médio incompleto; EMC - ensino médio completo; ESC - ensino superior completo. 
acompanhamento de seus sinais e sintomas. Portanto, o sistema de saúde no Brasil, de forma geral, ainda precisa se preparar para dar suporte a esta população Que adoece e também para sua família ${ }^{(1)}$.

O diagnóstico de uma doença é fato corrieueiro nos consultórios médicos, Quando finalizado, pode resultar em sentimentos de surpresa, preocupação e até indignação em um primeiro momento, pois imediatamente vêem a mente sentimentos negativos e perguntas sem resposta. Daí, até a aceitação existe um longo caminho a ser percorrido, em geral árduo e complexo, onde a convivência com a doença e seus sintomas acontece de forma particular para cada individuo.

Seis entrevistados referiram Que receberam o diagnóstico, ou tiveram a associação de seus sintomas à DP, pelo próprio médico Que procuraram. Em três casos, houve a indicação médica por outras pessoas que já conheciam a doença.

"Quando me alertaram pra eu cuidar com isso ai, na rua, a vizinhança, me falaram para cuidar Que era Parkinson, Que não sara tem que tomar remédio a vida inteira, e eu nunca tinha ouvido falar disso ai, desta doença, nunca na minha vida, ai eu cuidei, fui no médico do municipal, consultei duas vezes e ele falou Que era Parkinson e passou remédio." (Marron)

É interessante observar Que em um caso, a própria paciente, por conhecer a doença, se auto-diagnosticou, passou por todo o processo de aceitação, para depois procurar a confirmação do diagnóstico com um profissional médico.

“Intuição, eu achei Que era e já comecei aceitar que era, porQue a gente acha Que doença de Parkinson é o bicho, Que você vai se acabar... Depois de dois anos tive a confirmação do medico, todo mundo dizia Que não era, não era, eu sabia Que era..." (Vermelho)

A maioria dos parkinsonianos, antes de procurar ajuda médica, já haviam começado a apresentar alguns sinais e sintomas Que indicavam alguma desordem corporal. Em alguns casos o reconhecimento destes sinais e sintomas foi feito por pessoas do convívio mais próximo.

“Começou pela tremedeira, começou a tremer e não conseguia segurar direito o garfo, faca... ai foi ao médico que constatou a doença de Parkinson." (Azul C)

“Sentia que ela tava andando diferente..." (Branco C)

“... passou um tempo e ele sempre falava que o lado esquerdo dele tava travado, ficando travado, ai eu me preocupei..." (Amarelo C)

A comunicação do diagnóstico de uma doença crônica deve ser mais bem elaborada pelos profissionais de saúde, pois a forma com Que se passa o diagnóstico norteia os sentimentos e atitudes Que acompanharão indivíduos e familiares no enfrentamento da doença.

No primeiro contato com o diagnóstico, é muito importante a disposição do profissional para esclarecer dúvidas relacionadas com o Quadro clinico e também em permitir ao paciente e familiares manifestarem seus sentimentos relacionados com a notícia da doença. Muitas vezes uma consulta médica esclarecedora, em Que há valorização da compreensão dos familiares a cerca do assunto tratado, ao invés de uma consulta do tipo intervencionista, em Que há priorização de procedimentos e medicalização, é mais importante, pois observamos uma dificuldade das famílias e parkinsonianos entenderem e enfrentarem esta situação de infortúnio, devido à falta de conhecimento( ${ }^{(1)}$. Portanto, neste momento é importante valorizar mais as atitudes e o relacionamento com os pacientes e familiares, do Que as intervenções em $\mathrm{si}^{(10)}$.

A atitude do profissional tanto pode tranqüilizar o individuo frente as mudança em sua vida, como piorar o estado de saúde emocional, tal eual aconteceu com Rosa Que foi informada do diagnóstico pelo telefone, de forma bastante brusca e desumana, fato este Que exacerbou sentimentos negativos frente à doença.

“... dois dias depois ele me ligou, eu estava sozinha em casa, atendi ao telefone e ele disse assim: 'Queria Ihe avisar que a senhora está com parkinsonismo precoce, aumenta a dose daquela receita que te dei, tome duas vezes ao dia e volte daQui 90 dias". Eu cai no sofá, chorei, chorei, chorei... Quase morri de chorar, meu marido chegou eu estava chorando, enorme." (Rosa)

Em outro momento, Quando recebeu melhores informações a respeito da doença, a mesma pessoa passou a encarar a doença de outra forma.

“... e disse que eu tinha o parkinsonismo precoce, Que não era o fim do mundo, que acabou a vida, nada disso, disse para eu me cuidar muito bem e se preocupar com a qualidade de vida e Que eu vou morrer com isso e não disso. Mostrou todos os medicamentos, explicou tudo, me tranqüilizou, contou casos engraçados, foi super otimista. Me senti bem melhor. "(Rosa)

Portanto, a boa informação, caracterizada pela adoção de uma atitude humanitária e empática, ameniza a noticia e favorece a aceitação da situação e, ao mesmo tempo, permite Que a mesma seja encarada de forma mais amena.

“...ele falou assim...Que eu tinha uma doença Que não tinha cura, tem controle, mas não tem cura, depende um pouco da minha cabeça, ele disse que tinha que me tranqüilizar, ficar calmo, ficar sossegado..." (Azul)

Sendo assim, urge uma mudança na abordagem profissional. Faz-se necessário se colocar no lugar do outro e também procurar atender tanto a necessidade do doente Quanto a de sua família em relação à esclarecimentos desde o aparecimento da doença, seu percurso e evolução clínica. Ademais, toda a equipe multiprofissional envolvida no suporte ao parkinsoniano e sua família, precisa tratar a doença de forma positiva, incentivando-os a uma vivência mais otimista e humana.

O diagnóstico do Parkinson é clinico, e geralmente o tremor constitui a primeira e mais marcante manifestação. Posteriormente ocorre o aparecimento de rigidez, bradicinesia e instabilidade 
postural, sempre de forma assimétrica. Contudo, alguns sintomas não clássicos também costumam aparecer $\mathrm{e}$ isto pode dificultar $\mathrm{e}$ até retardar o diagnóstico, principalmente naqueles indivíduos que desenvolvem o parkinsonismo precoce, ou seja, antes dos 40 anos. Um destes sintomas é a dor, muito comum em outras patologias e Que confunde os próprios profissionais( ${ }^{(1)}$.

Os sinais e sintomas são percebidos, muitas vezes, primeiramente pela família. De fato a família é a primeira a reconhecer a presença de sinais e sintomas de alteração em seus membros, mesmo Quando estes são imperceptíveis ao portador e aos demais, eles parecem evidente para a família, dada a proximidade e convívio diário ${ }^{(2)}$. A família, portanto, pode ser uma grande aliada, não só no reconhecimento da doença, mas também no êxito do tratamento dos doentes parkinsonianos, sendo o fator externo de maior importância para a aceitação, organização e adaptação às dificuldades e limitações impostas pela doença ${ }^{(5)}$. A família contribui desde a simples detecção dos sintomas, como participa de todo o processo de aceitação até convivência com a doença.

\section{Percalços e sentimentos após o diagnóstico da doença}

A deficiência ou total falta de conhecimento sobre a doença por ocasião do diagnóstico, foi referida por oito pacientes e sete familiares. Este fato, tanto pode desencadear uma reação de normalidade ou extremo desespero.

"Me senti assustada, porque não conhecia muito bem o Parkinson, mas sabia que a pessoa tremia muito, né..." (Lilás)

“Sabe o que é... eu não sabia o Que era a doença de Parkinson, depois que eu fiquei sabendo. Acho que se eu conhecesse tinha tomado um choque, e o médico falou que era só tratar. Mas depois que eu via as outras pessoas, que treme bastante, eu fiQuei assustada. Não assustei na hora porQue não conhecia..." (Branco)

"Já sabia mais ou menos, não sabia muito sobre a doença não. E não conhecia ninguém Que tinha..." (Verde C)

Os sentimentos emergidos e as reações diante da noticia de uma doença crônica são muitas vezes associados à informação e conhecimento Que se tem a respeito de sua evolução e progressão. Os familiares Que já haviam tido algum contato com a DP, a experiência não havia sido muito positiva, potencializando o medo e o surgimento de sentimentos negativos.

"Não conhecia ninguém. O primeiro que eu vi foi um homem aqui, até que ele morreu... vixi, deu até dó... (Marron C)"

“... teve um amigo em Mamborê Que teve a doença , mas ela evoluiu muito rápido, a ponto de ... parece Que ele esta numa situação bem difícil. Diz que ele ta vivo ainda e já tem mais de 20 anos a doença, mas parece que ta ruim, Que treme o corpo inteirinho." (Amarelo C)

O significado da doença para o paciente e sua família envolve as dimensões culturais, sociais e psicológicas dos problemas de saúde e do contexto em Que aparece ${ }^{(12)}$. A maneira com Que as pessoas interpretam e respondem aos seus problemas de saúde é muito mais amplo do Que imaginamos. Para os parkinsonianos, os sentimentos gerados no momento do diagnóstico são bem diversificados, mas sempre negativos. Estes sentimentos podem ser dissipados pela presença da família, Que encoraja para Que o ente não se sinta isolado, desamparado e desanimado ${ }^{(5)}$. Porém, nem sempre a família esta junto no momento do diagnóstico, neste estudo, por exemplo, metade dos indivíduos estava sozinho nesta ocasião. De Qualquer forma, o Que ficou evidenciado é Que independente de estar ou não acompanhado, esta situação suscita o surgimento de sentimentos diversos, revelando ao individuo que algo errado e complexo está ocorrendo.

A não aceitação, tristeza, revolta, raiva, medo da dependência, depressão, decepção por saber o prognóstico incurável da doença, foram muitas as reações referidas, revelando a dificuldade de se encarar mudanças.

“Vixi, foi a mesma coisa Que jogar um balde de água fria em um cara todo Quente... foi um desânimo, abateu um pouco né... foi difícil de aceitar, até tive que tomar um medicamento... mas ai Quando eu não estou aceitando as coisas eu chuto a porta, xingo!!! Na verdade eu não aceito até hoje, porQue eu trabalhei a vida toda, igual um louco, tive uma construtora, construí este prédio, trabalhei muito..." (Verde)

"Muito mal, porque eu, porque eu, porque eu... Que eu ia ficar toda torta daqui dois anos. Fiquei muito mal, só pensamentos negativos, muito mal, fieuei um mês assim..." (Rosa)

"Dá aquele baque, a gente fica meio triste, depois tem que se conformar... pensar que tem que ficar tomando remédio, o medico falou Que não mata, mas não sara. Fiquei uns 6 meses triste, não muito porQue a gente sabe Que não sara mesmo..." (Amarelo)

“...Fiquei aborrecido, porque achei que era uma doença que sarava, né." (Marron)

A convivência com a doença de Parkinson representa iniciar um novo processo na vida dos portadores e seus familiares. Inicialmente, o conhecimento do diagnóstico provoca grande impacto, porém aos poucos, a necessidade de conviver com a situação por toda a vida vai sendo incorporada. O processo de enfrentamento da nova situação e condição de vida não é fácil e normalmente é acompanhado de sofrimento, tristeza, medo, angústia, incertezas e desânimo. Em meio à negação, à aceitação ou não, ou conformação com a situação, surge a necessidade de operar alguma mudança interna e pessoal ${ }^{(5)}$.

“Nos primeiros 6 meses eu entrei numa depressão, só de pensar na dependência..." (Vermelho)

A depressão referida em alguns depoimentos pode ser um fator de risco para a DP, assim como a DP também é um fator de risco para depressão, pois os parkinsonianos apresentam uma maior vulnerabilidade para o desenvolvimento desta, o Que influencia não 
na Quantidade, mas na Qualidade dos déficits cognitivos, maior deterioração das atividades de vida diária e progressão mais rápida da $\mathrm{DP}^{(13)}$.

Por outro lado, observamos Que entre os indivíduos em estudo, à despeito do pouco ou nenhum conhecimento Que possuíam sobre a doença, por ocasião do diagnóstico, não emergiu entre eles o medo da morte.

“...fiquei normal porque o Dr. explicou que não tinha cura, mas tinha controle, Que podia durar 10,20,50 anos, o mal de Parkinson não mata, mata se você não se controlar, se você se controlar, de Parkinson não vai morrer..." (Azul)

A aceitação e convívio devem ser incentivadas pelos profissionais de saúde Que dão suporte ao parkinsoniano, da mesma forma Que, ante a progressividade da doença, a manutenção da Qualidade de vida e independência deve sempre ser a meta perseguida. Ademais, precisam considerar Que os familiares também merecem atenção, pois demonstraram surpresa e preocupação no momento do diagnóstico, por desconhecerem a doença e principalmente porQue serão eles Que acompanharão e apoiarão o indivíduo daQui para frente.

"Pra gente foi um susto, porQue a gente não tinha noção do Que era o Parkinson, a gente achava Que era outra doença assim, normal, Que não ia afetar tanto como afetou..." (Lilás C)

A literatura aponta Que as emoções geradas Quando se descobre a presença de uma doença crônica, tanto para o portador, como para a família, são semelhantes em QualQuer faixa etária, dentre elas estão a negação, a tendência a minimizar seus efeitos, raiva e frustração pela limitação imposta pela doença, sintomas depressivos, culpa, procura de soluções impossíveis, entre outros ${ }^{(14)}$.

Alguns familiares demonstraram um sentimento de conformação, mas ao mesmo tempo parecem não Querer encarar a realidade.

“...vou levando assim, Quero fazer de conta que não é nada, faço de conta que não é nada... pra mim, eu peço força pra Deus, mas eu botei na minha cabeça Que não é nada, pra não deixar ele triste e nem eu..." (Amarelo C)

“Ah... tem que tocar o barco né, levar a vida, cuidar..." (Rosa C)

Outros, inclusive se mostraram até mesmo alheios ao problema, talvez por falta de entendimento ou por não manter uma relação muito próxima com o individuo parkinsoniano.

"Eu senti normal, não achei nada, para mim não fez diferença. Ele Que não se conformava." (Verde C)

“Fiquei na minha, porque o negócio é cuidar, né...” (Laranja C)

E por fim, a possibilidade do individuo com Parkinson vir a apresentar algum nível de dependência, em alguns casos já foi o suficiente para surgirem conflitos interpessoais, desde o momento do diagnóstico. Isto foi particularmente observado nos casos em Que já existia desarmonia no relacionamento conjugal.
"Fazer o Quê? A gente fica sentida né, porQue Quando começou a dar mesmo o tremor, eu tinha Que até abotoar as roupas dele, os botão, a braguilha, tinha que abotoar porque ele não conseguia...fiquei sentida porque agora dano tudo né, do jeito Que ele reclamava, ai agora ia reclamar mais..." (Marron C)

De fato, conflitos existentes antes do aparecimento da doença podem se intensificar neste novo momento, causando ansiedade e frustração nas pessoas envolvidas, principalmente nos cônjuges cuidadores $^{(1)}$.

Encontramos casos em Que houve uma rápida aceitação e aprenderam a conviver com a doença, outros vivem um período maior de revolta e não aceitação. A busca de forças, na família ou em si mesmo faz parte desta trajetória.

“... depois sacudi a poeira e dei a volta por cima, chega de chororô e fui cuidar de mim... porque a gente se vê no outro, por mais que digam que cada um é diferente, é a mesma doença, é inerente, a gente tá numa realidade diferente de vocês, compartilhamos mesmos sentimentos. Eu não sou de ficar curtindo muito não, eu fico com raiva, choro, e já balanço e levanto, vou produzir enquanto eu posso..." (Rosa)

"Quando o médico me confirmou eu já tinha aceitado e tava consciente, só vamos tomar o remédio e se cuidar. Do mais entreguei a Deus... fazer o Quê? E vamos esperar a cura vir..." (Vermelho)

E ao Que parece, a convivência com outras pessoas Que enfrentam o mesmo problema constitui um aliado importante para Que o Parkinsoniano encontre forças para continuar lutando e também na aceitação da doença com suas limitações.

"Mas agora tô melhor, a gente vê gente pior. Um tremendo a perna, o braço, tem gente pior Que a gente e tá bem, tá contente né, e um pega na mão do outro e se abraça e é aquela amizade e fala que aqui é a turma dos tremedor, eu acho que sou feliz, porque se eu fosse Que nem os outros..." (Marron)

O familiar também vivencia esta busca, principalmente para passar ao parkinsoniano a imagem de naturalidade e não gravidade da doença.

"Eu... tive que dar força pra ele, fazer de conta que nada estava acontecendo. Mas Deus me deu tanta força, Que parece Que ele me anestesiou na hora, Deus me anestesiou, parece que estou anestesiada até hoje..." (Amarelo C)

O impacto da descoberta da presença de uma doença crônica gera inúmeras reações e expectativas, revelando uma diversidade de sentimentos e comportamentos. Esta dura realidade traz situações novas, onde o parkinsoniano e a família se deparam com coisas Que não entendem, com as instabilidades da doença e principalmente com o fato de saber Que a doença é incurável, Que o acompanhará em suas relações e no seu cotidiano, o resto da vida, independente de sua vontade. É conviver com algo Que a única coisa a fazer é cuidar-se, pois tudo gira em torno do controle e não da cura. 


\section{CONSIDERAÇÕES FINAIS}

A família vivência todas as mudanças e sentimentos gerados pela presença de uma doença crônica em seu ambiente. E Quando nos referimos a doença de Parkinson, estas dificuldades são multiplicadas, pois além da sua cronicidade, trata-se de uma doença neurodegenerativa e progressiva, Que afeta o físico, mental e social do individuo, gerando dependências e necessidades vivenciadas também pela família.

O impacto do diagnóstico é o primeiro momento de dificuldade e Que exige uma positiva superação para o bom convívio com a doença. Vimos Que existe ainda falta de informação Quanto ao diagnóstico do Parkinson, tanto por parte profissional, Quanto para a comunidade. Pouco se conhece sobre a doença e seus sintomas, atrasando desta forma o diagnóstico correto e inicio precoce do tratamento.

Notamos Que neste primeiro contato com o diagnóstico, foi crucial o esclarecimento do Quadro clinico por parte do profissional de saúde, pois a reação das pessoas frente ao diagnostico de uma doença crônica, pode ser muito mais complexa do que imaginamos. Os sentimentos são diversificados, mas Quase Que exclusivamente negativos, como a não aceitação, tristeza, revolta, raiva, medo da dependência, depressão e decepção por saber o prognóstico incurável da doença.

Quando se depara com estas dificuldades, percebemos uma busca de forças na família ou em si mesmo, fazendo parte deste momento de aceitação e refletindo na compreensão mutua, visto Que o Parkinson, como outras doenças crônicas, não afetam apenas o portador, mas toda a família envolvida.

Portanto, cabe aos profissionais de saúde buscar amenizar o impacto da doença para o paciente e para a família, por meio de atitudes humanitárias e esclarecedoras no momento de comunicar o diagnóstico. Além disso, no decorrer do tratamento procurar dar suporte técnico de reabilitação e cuidado, dar apoio psicosocial e sobretudo contribuir para a manutenção de uma boa Qualidade de vida para o parkinsoniano e sua família.

\section{REFERÊNCIAS}

1. Luzardo AR, Waldman BF. Atenção ao familiar cuidador do idoso com doença de Alzheimer. Acta Scientiarum Health Sciences 2004; 26(1): 135-45.

2. Marcon SS, Radovanovic CAT, Waidman MAP, Oliveira MLF, Sales CA. Vivência e reflexões de um grupo de estudos junto às famílias Que enfrentam a situação crônica de saúde. Texto Contexto Enferm 2005; 14:116-24.

3. Dowding $\mathrm{CH}$, Shenton $\mathrm{CL}$, Salek SS. A Review of the health-related Quality of life and economic impact of Parkinson's Disease. Drugs Aging 2006; 23(9): 693721.

4. Paula RF, Teixeira-Salmela LF, Faria CDCM, Brito PR, Cardoso F. Impact of na exercise program on physical, emotional, and social aspects of Quality of life of individuals with Parkinson's disease. Mov Disor 2006; 2 I (8): 1073-7.

5. Gonçalves LGT, Alvarez AM, Arruda MC. Pacientes portadores da doença de Parkinson: significado de suas vivências. Acta Paul Enferm 2007; 20(1): 62-8.

6. Cecagno S, Souza MD, Jardim VMR. Compreendendo o contexto familiar no processo saúde-doença. Acta Scientiarum Health Sciences 2004; 26(1): 107-12.

7. Lavinsky AE, Vieira TV. Processo de cuidar de idosos com acidente vascular encefálico: sentimento dos familiares envolvidos. Acta Scientirum Health Sciences 2004; 26(1): 41-5.

8. Hoehn, MM; Yahr MD. Parkinsonism: onset, progression and mortality. Neurology 1967; 17: 427-42.

9. Minayo MCS. O desafio do conhecimento: pesquisa Qualitative em saúde. $10^{a}$ edição. São Paulo: Hucitec; 2007.

10. Cho HI. Reviving the old sermon of medicine with the placebo effect. Rev Bras Psieuiatr 2005; 27(4): 336340.

11. Sekeff-Sallem FA, Barbosa ER. Diagnostic pitfalls in Parkinson's disease. Are Neuropsieuiatr 2007; 65(2A): 348-351.

12. Pinto MH, Zago MMF. A compreensão do significado cultural do aneurisma cerebral e do tratamento atribuídos pelo paciente e familiares: um estudo etnográfico. Rev Latino-am Enfermagem 2000; 8(1): 51-56.

13. Silberman CD, Laks I, Rodrigues CS, Engelhardt E. Uma revisão sobre depressão como fator de risco na doença de Parkinson e seu impacto na cognição. Rev Psiquiatr 2004; 26(1): 52-60.

14. Moreira PL, Dupas G. Vivendo com o diabetes: experiência contada pela criança. Rev Latino-am Enfermagem 2006; 14(1): 25-32. 